University of Wollongong

Research Online

Australian Institute for Innovative Materials -

Papers

Australian Institute for Innovative Materials

$1-1-2016$

Two-dimensional cobalt-/nickel-based oxide nanosheets for highperformance sodium and lithium storage

\author{
Dan Zhang \\ University of Wollongong, Zhejiang University, dz966@uowmail.edu.au \\ Wenping Sun \\ University of Wollongong, wenping@uow.edu.au \\ Zhihui Chen \\ Zhejiang University \\ Yu Zhang \\ University of Wollongong, azhang@uow.edu.au \\ Wenbin Luo \\ University of Wollongong,wl368@uowmail.edu.au
}

See next page for additional authors

Follow this and additional works at: https://ro.uow.edu.au/aiimpapers

Part of the Engineering Commons, and the Physical Sciences and Mathematics Commons

Research Online is the open access institutional repository for the University of Wollongong. For further information contact the UOW Library: research-pubs@uow.edu.au 


\title{
Two-dimensional cobalt-/nickel-based oxide nanosheets for high-performance sodium and lithium storage
}

\author{
Abstract \\ Two-dimensional (2D) nanomaterials are one of the most promising types of candidates for energy- \\ storage applications due to confined thicknesses and high surface areas, which would play an essential \\ role in enhanced reaction kinetics. Herein, a universal process that can be extended for scale up is \\ developed to synthesise ultrathin cobalt-/nickel-based hydroxides and oxides. The sodium and lithium \\ storage capabilities of $\mathrm{Co} 3 \mathrm{O} 4$ nanosheets are evaluated in detail. For sodium storage, the $\mathrm{Co} 3 \mathrm{O} 4$ \\ nanosheets exhibit excellent rate capability (e.g., $179 \mathrm{~mA} h \mathrm{~g}_{i} 1$ at $7.0 \mathrm{~A} \mathrm{~g}_{i} 1$ and $150 \mathrm{~mA} \mathrm{~h} \mathrm{~g}_{i} 1$ at $10.0 \mathrm{~A}$ \\ $\left.g_{i} 1\right)$ and promising cycling performance $\left(404 \mathrm{~mA} h\right.$ gi 1 after 100 cycles at $\left.0.1 \mathrm{~A}_{i} 1\right)$. Meanwhile, very \\ impressive lithium storage performance is also achieved, which is maintained at $1029 \mathrm{~mA} \mathrm{~h} \mathrm{~g}_{i} 1$ after 100 \\ cycles at $0.2 \mathrm{Ag}_{i} 1$. NiO and $\mathrm{NiCo} 2 \mathrm{O} 4$ nanosheets are also successfully prepared through the same \\ synthetic approach, and both deliver very encouraging lithium storage performances. In addition to \\ rechargeable batteries, 2D cobalt-/nickel-based hydroxides and oxides are also anticipated to have great \\ potential applications in supercapacitors, electrocatalysis and other energy-storage-/-conversion-related \\ fields.
}

\section{Keywords}

two-dimensional, nanosheets, storage, high-performance, sodium, lithium, cobalt-/nickel-based, oxide

\section{Disciplines}

Engineering | Physical Sciences and Mathematics

\section{Publication Details}

Zhang, D., Sun, W., Chen, Z., Zhang, Y., Luo, W., Jiang, Y. \& Dou, S. Xue. (2016). Two-dimensional cobalt/nickel-based oxide nanosheets for high-performance sodium and lithium storage. Chemistry - A European Journal, 22 (50), 18060-18065.

\section{Authors}

Dan Zhang, Wenping Sun, Zhihui Chen, Yu Zhang, Wenbin Luo, Yinzhu Jiang, and Shi Xue Dou 


\title{
Two-dimensional Cobalt/Nickel-Based Oxide Nanosheets for High-Performance Sodium and Lithium Storage
}

\author{
Dan Zhang, ${ }^{[a, b]}$ Wenping Sun, ${ }^{[}{ }^{[b]}$ Zhihui Chen, ${ }^{[a]}$ Yu Zhang, ${ }^{[b]}$ Wenbin Luo, ${ }^{[b]}$ Yinzhu Jiang, ${ }^{*}{ }^{[a]}$ Shi Xue \\ Dou $^{[b]}$
}

\begin{abstract}
Two-dimensional (2D) nanomaterial is one of the most promising candidates for energy storage applications due to its confined thickness and high surface area, which would play an essential role for enhanced reaction kinetics. In this work, a universal process that can be extended to scale-up is developed for synthesizing ultrathin $\mathrm{Co} / \mathrm{Ni}$-based hydroxides and oxides. The sodium and lithium storage capability of $\mathrm{Co}_{3} \mathrm{O}_{4}$ nanosheets are evaluated in detail. For sodium storage, the $\mathrm{Co}_{3} \mathrm{O}_{4}$ nanosheets exhibit excellent rate capability (e.g. $179 \mathrm{~mA} \mathrm{~h} \mathrm{~g}^{-1}$ at $7.0 \mathrm{~A} \mathrm{~g}^{-1}$ and $150 \mathrm{~mA} \mathrm{~h} \mathrm{~g}^{-1}$ at $10.0 \mathrm{~A} \mathrm{~g}^{-1}$ ) and promising cycling performance (404 $\mathrm{mA} \mathrm{h} \mathrm{g}{ }^{-1}$ after 100 cycles at $0.1 \mathrm{~A} \mathrm{~g}^{-1}$ ). Meanwhile, very impressive lithium storage performance is also achieved, which maintains 1029 $\mathrm{mA} \mathrm{h} \mathrm{g}{ }^{-1}$ after 100 cycles at $0.2 \mathrm{~A} \mathrm{~g}^{-1}$. $\mathrm{NiO}$ and $\mathrm{NiC}_{2} \mathrm{O}_{4}$ nanosheets are also successfully prepared with the same synthesis approach, and both deliver very encouraging lithium storage performance. In addition to rechargeable batteries, the $2 \mathrm{D} \mathrm{Co/Ni-based} \mathrm{hydroxides}$ and oxides are also anticipated to have great potential applications in supercapacitors, electrocatalysis, and other energy storage/conversion-related fields.
\end{abstract}

\section{Introduction}

Two-dimensional (2D) nanomaterials are highly desirable for energy storage and conversion, electronics, photocatalysis, biosensing, etc., due to their exciting physical, chemical or electronic properties, which can be attributed to their confined atomic thickness, high specific surface area and quantum confinement of electrons in 2D plane. [1] Enormous progresses of graphene-based 2D nanostructures have been achieved in various applications in the past decade. ${ }^{[2]}$ These achievements have sparked numerous interests of $2 \mathrm{D}$ inorganic compounds, such as metal oxides, metal chalcogenides and others..$^{[3]}$

Lithium/sodium ion batteries (LIBs/SIBs) are springing rapidly as new generation devices for energy storage systems as well as electric vehicles. ${ }^{[4]}$ Transition metal oxides (TMOs) and chalcogenides (TMCs) stand out as promising alternative

[a] Dr. D. Zhang, Z. Chen, Prof. Y. Jiang

State Key Laboratory of Silicon Materials, Key Laboratory of

Advanced Materials and Applications for Batteries of Zhejiang

Province and Department of Materials Science and Engineering,

Zhejiang University

Hangzhou, Zhejiang 310027(P. R. China)

E-mail: yzjiang@zju.edu.cn

[b] Dr. D. Zhang, W. Sun, Y. Zhang, W. Luo, Prof. S. X. Dou DepartmentInstitute for Superconducting and Electronic Materials, University of Wollongong

Wollongong, NSW 2522 (Australia)

E-mail:wenping@uow.edu.au

Supporting information for this article is given via a link at the end of the document. anode candidates for LIBs/SIBs due to the higher theoretica capacity based on the conversion reaction mechanism. ${ }^{[5]}$ However their practical use is impeded by poor cycling stability caused by inevitable volume change and the sluggish reaction kinetics. ${ }^{[5 a, b, 6]}$ In regarding to sodium storage, the sluggish reaction kinetics becomes more significant, and hence the delivered capacities are much lower than the theoretical values. ${ }^{[4 a]}$ In order to address these issues, tremendous effort has been devoted to developing more efficient and robust electrode materials with various nanostructures, such as nanospheres, nanofibers, nanoflakes, nanosheets, and so forth. ${ }^{[5 c, 7]} 2 \mathrm{D}$ nanosheet is one of the most efficient nanostructures for enhanced lithiation/delithiation or sodiation/desodiation reactions, which can provide significantly shortened ion and electron diffusion pathway, sufficient electrode/electrolyte contact, abundant electrochemical active sites and high mechanical flexibility to endow long-term cycling stability. ${ }^{[3 a, d, 8]}$

Driven by the fascinating properties and promising applications, much effort has been devoted to exploring various kinds of synthetic strategies to produce $2 \mathrm{D}$ nanomaterials. ${ }^{[9]}$ So far, a scalable and cost-effective approach to prepare homogenous especially large-area 2D inorganic nanomaterials (e.g., metal oxides nanosheets), is still a great challenge. At early stages, 2D nanostructures are dominantly obtained via the exfoliation method, in which single or few-layer structures are generated by intercalating metal ions or solvent molecules into the parent layered structures. Although exfoliation represents a versatile and scalable route, it is usually uncontrollable in terms of the uniformity of size/shape, thickness and lateral dimension. ${ }^{[10]}$ Another popular method to fabricate 2D nanomaterials is high-temperature chemical vapour deposition (CVD), which favours the synthesis of $2 \mathrm{D}$ nanomaterials with high quality and purity. However, CVD is closely dependent on the substrate accompanied with low yield and high cost. ${ }^{[11]}$ Oilphase synthesis with capping agent is a low-cost and highly reliable process, which can efficiently produce $2 \mathrm{D}$ transition metal chalcogenide with fewer defects and less crystalline disorder than other methods. However, it is not easy to obtain the desired stoichiometry and is very hard to be scaled up. [9a, 12]

Herein, we report a facile and scalable approach to synthesize high-quality $2 \mathrm{D} \quad \mathrm{Co}_{3} \mathrm{O}_{4}$ nanosheets under mild hydrothermal reactions followed by a quick heat treatment process. The nanosheet morphology is well inherited from the layered structured 2D $\mathrm{Co}(\mathrm{OH})_{2}$ nanosheets. Notably, this approach could be extended to the synthesis of other analogue nanosheets including binary and ternary transition metal oxides ( $\mathrm{NiO}$ and $\mathrm{NiCO}_{2} \mathrm{O}_{4}$ ). As anode materials for $\mathrm{LIBs} / \mathrm{SIBs}$, the $2 \mathrm{D}$ nanosheets show extraordinary electrochemical performance in terms of specific capacity, rate capability and cycling life. 


\section{Results and Discussion}
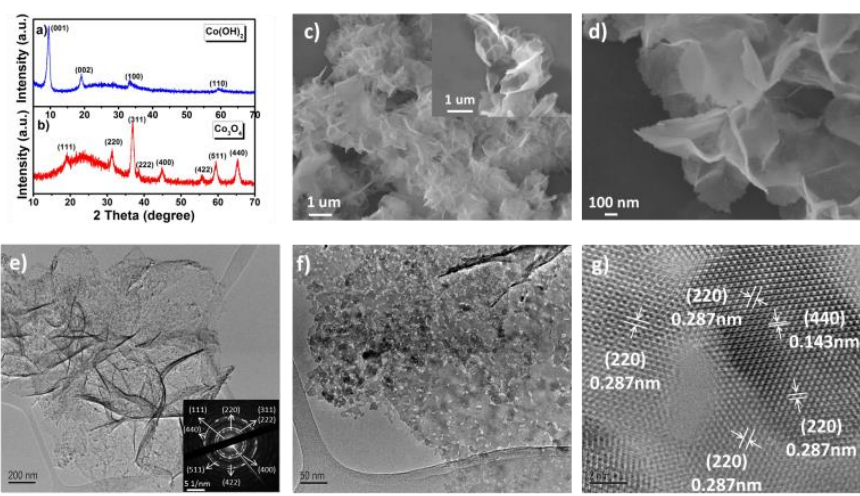

Figure 1. Figure Caption. XRD patterns of as-prepared products: (a) $\mathrm{Co}(\mathrm{OH})_{2}$ and (b) $\mathrm{Co}_{3} \mathrm{O}_{4}$. SEM images of as-prepared products: (c) $\mathrm{Co}(\mathrm{OH})_{2}$ and (d) $\mathrm{Co}_{3} \mathrm{O}_{4}$. (e) TEM, (f) High magnification TEM and (g) HRTEM image of $\mathrm{Co}_{3} \mathrm{O}_{4}$ nanosheets. The inset in Fig. 1c and e is the high magnification SEM image and SAED pattern, respectively.

Figure 1a shows the X-ray diffraction (XRD) result of the asprepared product synthesized by the solvothermal process at $120{ }^{\circ} \mathrm{C}$ for $4 \mathrm{~h}$. All the diffraction peaks can be indexed to hexagonal layered $\alpha-\mathrm{Co}(\mathrm{OH})_{2}$ (JCPDS card no. 51-1731). Figure 1c shows that $\alpha-\mathrm{Co}(\mathrm{OH})_{2}$ possesses graphene-like 2D morphology. From the inset of Figure 1c, we can see that the nanosheets are uniform and in micron plane size. The crumple of the nanosheets can be ascribed to the consequence of accommodating the excessive surface energy. The thermal gravimetric analysis (TGA) curve of the $\alpha-\mathrm{Co}(\mathrm{OH})_{2}$ nanosheets are presented in Figure $\mathrm{S} 1$, which demonstrates two stages of weight loss within the temperature range of $50-450{ }^{\circ} \mathrm{C}$. The weight loss below $175^{\circ} \mathrm{C}$ is associated with the evaporation of absorbed water. The major weight loss occurs within the temperature range of $175-450{ }^{\circ} \mathrm{C}$, which is related to the decomposition and oxidization of $\alpha-\mathrm{Co}(\mathrm{OH})_{2}$ to $\mathrm{Co}_{3} \mathrm{O}_{4}$. According to the TGA result, the nominal formula of the as prepared product is calculated to be $\mathrm{Co}(\mathrm{OH})_{2} \cdot 0.5 \mathrm{H}_{2} \mathrm{O}$. Figure $1 \mathrm{~b}$ shows the XRD pattern of the product after calcining $\alpha-\mathrm{Co}(\mathrm{OH})_{2}$ at $300{ }^{\circ} \mathrm{C}$ for $2 \mathrm{~h}$. All the diffraction peaks are consistent with a cubic phase structure of $\mathrm{Co}_{3} \mathrm{O}_{4}$ (JCPDS Card NO. 65-3103). As shown in Figure 1d, the $\mathrm{Co}_{3} \mathrm{O}_{4}$ inherits the nanosheet morphology of $\alpha-\mathrm{Co}(\mathrm{OH})_{2}$, indicating the 2D graphene-like morphology can be well preserved after the mild heat treatment process. The TEM image shown in Figure1e further confirms the ultrathin characteristic as well as a typically wrinkle structure of $\mathrm{Co}_{3} \mathrm{O}_{4}$ nanosheets. The corresponding selected area electron diffraction (SAED) pattern (inset of Figure 1e) reveals the polycrystalline nature of the nanosheets, which can be indexed to (111), (220), (311), (222), (400), (422), (511) and (440) planes of cubic $\mathrm{Co}_{3} \mathrm{O}_{4}$, and is in high agreement with the XRD result. The high magnification TEM image in Figure if depicts the detailed morphology of one single nanosheet constructed with numerous nanoparticles and uniform nanosized holes $(2-10 \mathrm{~nm})$, which will provide high surface areas for electrolyte/electrode contact and sufficient space for releasing the strain caused by volume changes over cycling. The high resolution TEM (HRTEM) image (Figure 1g) shows typical lattice fringes with interplanar distances of 0.143 and $0.287 \mathrm{~nm}$, which can be assigned to the (220) and (440) planes of cubic $\mathrm{Co}_{3} \mathrm{O}_{4}$. Figure $\mathrm{S} 2$ shows the nitrogen adsorption-desorption isotherms and the corresponding pore size distributions of as prepared $\mathrm{Co}_{3} \mathrm{O}_{4}$ nanosheets.

To evaluate the sodium storage ability of the ultrathin $\mathrm{Co}_{3} \mathrm{O}_{4}$ nanosheets, coin-type half cells were assembled and a series of electrochemical measurements were carried out at room temperature. Cyclic voltammetry (CV) test of the cell was conducted at $0.1 \mathrm{mV} \mathrm{s}^{-1}$ in the voltage range of 0.01-3.0 V (vs. $\mathrm{Na} / \mathrm{Na}^{+}$) (Figure 2a). During the initial cathodic scan, two broad reduction peaks appear. The cathodic peak at $\sim 1.03 \mathrm{~V}$ disappearing in the following cycles could be ascribed to the formation of an irreversible solid electrolyte interphase (SEI) layer. Another cathodic peak at $\sim 0.47 \mathrm{~V}$ in the first cycle corresponds to the reduction of $\mathrm{Co}_{3} \mathrm{O}_{4}$ to metallic Co accompanied by the electrochemical formation of $\mathrm{Na}_{2} \mathrm{O}$. In the following anodic scan, there is a broad peak at $\sim 1.63 \mathrm{~V}$, which is related to the re-oxidation of $\mathrm{Co}$ to $\mathrm{Co}_{3} \mathrm{O}_{4}$ and decomposition of $\mathrm{Na}_{2} \mathrm{O}$. Theoretically, sodium storage is achieved by the conversion reaction for $\mathrm{Co}_{3} \mathrm{O}_{4}$, with the formation of $\mathrm{Co}$ and $\mathrm{Na}_{2} \mathrm{O}$ (sodiation reaction) and the reformation of $\mathrm{Co}_{3} \mathrm{O}_{4}$ (desodiation reaction) as described by the following electrochemical reaction. ${ }^{[13]}$

$\mathrm{Co}_{3} \mathrm{O}_{4}+8 \mathrm{Na}^{+}+8 \mathrm{e}^{-} \leftrightarrow 4 \mathrm{Na}_{2} \mathrm{O}+3 \mathrm{Co}$

In the subsequent cycles, only one cathodic peak at $\sim 0.63 \mathrm{~V}$ can be observed, which can be attributed to the reduction of $\mathrm{Co}_{3} \mathrm{O}_{4}$. The CV curves overlapping in the third and fourth cycles demonstrate good electrochemical stability of $\mathrm{Co}_{3} \mathrm{O}_{4}$ nanosheets over cycling.

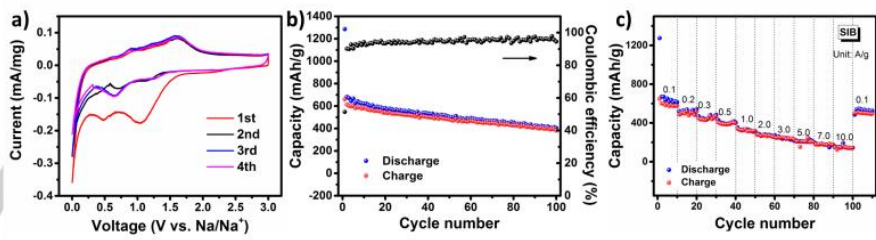

Figure 2. (a) $\mathrm{CV}$ curves of $\mathrm{CO}_{3} \mathrm{O}_{4}$ nanosheet electrode in the voltage window of 0.001-3.0 V (vs. $\mathrm{Na} / \mathrm{Na}^{+}$) at a scan rate of $0.1 \mathrm{mV} \mathrm{s}^{-1}$. (b) Cycling performance of $\mathrm{Co}_{3} \mathrm{O}_{4}$ nanosheets as anode materials of $\mathrm{SIB}$ at a current density of $100 \mathrm{~mA} \mathrm{~g}^{-1}$. (c) Rate capability of $\mathrm{Co}_{3} \mathrm{O}_{4}$ nanosheet electrode of SIB at different current rates in the voltage window of 0.01-3.0 V (vs. $\left.\mathrm{Na} / \mathrm{Na}^{+}\right)$.

Figure $2 \mathrm{~b}$ presents the cycling performance of the $\mathrm{Co}_{3} \mathrm{O}_{4}$ nanosheet electrode at a current density of $100 \mathrm{~mA} \mathrm{~g}^{-1}$ in the voltage range of $0.01-3.0 \mathrm{~V}$ (vs. $\left.\mathrm{Na} / \mathrm{Na}^{+}\right)$. The first discharge capacity $\left(1286 \mathrm{~mA} \mathrm{~h} \mathrm{~g}^{-1}\right)$ is higher than the theoretical capacity $\left(890 \mathrm{~mA} \mathrm{~h} \mathrm{~g}^{-1}\right)$, which is generally caused by the inevitable decomposition of electrolyte and the irreversible formation of SEl. ${ }^{[14]}$ Due to the significantly irreversible contribution, the first charge capacity is $661 \mathrm{mAh} \mathrm{g}^{-1}$, showing columbic efficiency of $51.4 \%$. The reversible capacity is lower than the theoretical value, which is in great part due to the relatively sluggish reaction (sodiation/desodiation) kinetics. However, it has to be mentioned that the reversible charge capacity is improved greatly as compared with the previous reports about $\mathrm{Co}_{3} \mathrm{O}_{4}$ anodes for sodium storage, e.g. hierarchical $\mathrm{Co}_{3} \mathrm{O}_{4}$ 
spheres/CNTs (487 $\mathrm{mA} \mathrm{h} \mathrm{g}^{-1}$ at $\left.160 \mathrm{~mA} \mathrm{~g}^{-1}\right),{ }^{[15]} 39$ mesoporous $\mathrm{Co}_{3} \mathrm{O}_{4}$ sheets/3D graphene $\left(375.5 \mathrm{~mA} \mathrm{~h} \mathrm{~g}^{-1}\right.$ at $\left.25 \mathrm{~mA} \mathrm{~g}^{-1}\right),{ }^{[16]}$ and $\mathrm{Co}_{3} \mathrm{O}_{4}$ nanopartciles@nitrogen-doped carbon (516 mA h g ${ }^{-1}$ at $\left.100 \mathrm{~mA} \mathrm{~g}^{-1}\right) \cdot{ }^{[17]}$ The $2 \mathrm{D}$ ultrathin morphology should play a key role in enhancing the sodiation/desodiation reaction kinetics and thereby specific capacity. It is clearly seen that the $\mathrm{Co}_{3} \mathrm{O}_{4}$ nanosheet electrode shows promising cycling performance, and the capacity maintains to be $404 \mathrm{~mA} \mathrm{~h} \mathrm{~g}^{-1}$ after 100 cycles, with a capacity retention of $\sim 60 \%$. It is noted that the cycling stability of this work without carbon-based matrix is also extraordinary compare to the aforementioned $\mathrm{Co}_{3} \mathrm{O}_{4}$ with other nanostructures as the Table $\mathrm{S} 1$ shows. The rate capability of the ultrathin $\mathrm{Co}_{3} \mathrm{O}_{4}$ nanosheet electrode is presented in Figure 2c. The electrode shows high reversible specific discharge capacity of 538,436 , $390,332,281,243$, and $208 \mathrm{~mA} \mathrm{~h} \mathrm{~g}^{-1}$ at different current densities of $0.2,0.3,0.5,1.0,2.0,3.0$ and $5.0 \mathrm{~A} \mathrm{~g}^{-1}$. Even when the current density is increased to as high as 7.0 and $10.0 \mathrm{~A} \mathrm{~g}^{-1}$, the reversible capacity maintains high retention of 179 and 150 $\mathrm{mA} \mathrm{h} \mathrm{g}^{-1}$, respectively. The cell still delivers a high capacity of $533 \mathrm{~mA} \mathrm{~h} \mathrm{~g}^{-1}$ when the current density is reversed to $0.1 \mathrm{~A} \mathrm{~g}^{-1}$. Gradually enlarged overpotential and shorten curves assigned to conversion reactions are observed as higher rates are employed which is a common characteristic of metal oxide based electrodes (Figure S3). The encouraging electrochemical performances indicate the unique superiority of $\mathrm{Co}_{3} \mathrm{O}_{4}$ nanosheets for sodiation/desodiation reaction, which provides
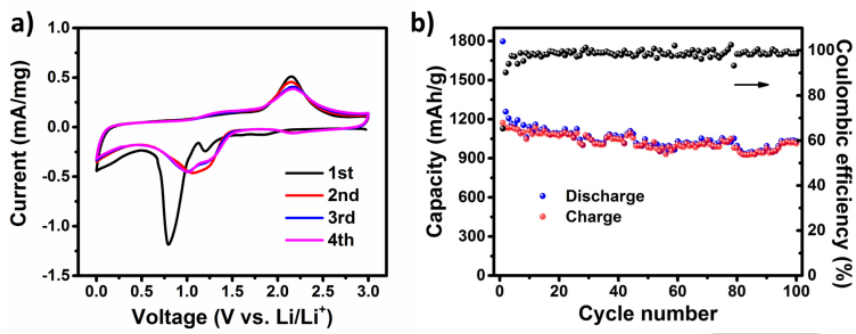

fast kinetics for $\mathrm{Na}^{+}$diffusion and charge transfer, and sufficient space for accommodating volume change.

Figure 3. (a) $\mathrm{CV}$ curves of $\mathrm{Co}_{3} \mathrm{O}_{4}$ nanosheet electode in the voltage window of 0.001-3.0 V (vs. $\mathrm{Li} / \mathrm{Li}^{+}$) at a scan rate of $0.1 \mathrm{mV} \mathrm{s}^{-1}$. (b) Cycling performance of $\mathrm{Co}_{3} \mathrm{O}_{4}$ nanosheets as anode materials of LIB at a current density of $200 \mathrm{~mA} \mathrm{~g}$

In addition to sodium storage, the lithium storage capability of $\mathrm{Co}_{3} \mathrm{O}_{4}$ nanosheets was also evaluated with the coin-type half cells. The CV curves was tested at a scan rate of $0.1 \mathrm{mV} \mathrm{s}^{-1}$ in the voltage range of $0.01-3.0 \mathrm{~V}\left(\mathrm{vs}\right.$. $\left.\mathrm{Li}^{-} \mathrm{Li}^{+}\right)$. As shown in Figure $3 \mathrm{a}$, two cathodic peaks are observed at 1.2 and $0.8 \mathrm{~V}$ in the first cycle, which correspond to the electrochemical reduction reaction of $\mathrm{Co}_{3} \mathrm{O}_{4}$ and the formation of SEI layer. The anodic peak at $2.15 \mathrm{~V}$ can be ascribed to the re-oxidation reaction to form $\mathrm{Co}_{3} \mathrm{O}_{4}$. The peaks in subsequent scans overlap, indicating the superiority of $\mathrm{Co}_{3} \mathrm{O}_{4}$ nanosheets as durable anode material for LIBs. It should be noted that, as compared with the case for sodium storage (Figure 2a), much intenser redox peaks are observed for lithium storage, indicating faster lithiation/delithiation reaction kinetics. The sluggish sodiation/desodiation reaction kinetic is mostly attributed to the larger ionic radius of sodium ions. ${ }^{[18]}$ The cycling performance of $\mathrm{Co}_{3} \mathrm{O}_{4}$ nanosheets for lithium storage at a current density of 0.2 $\mathrm{A} \mathrm{g}^{-1}$ is shown in Figure $3 \mathrm{~b}$. The first discharge capacity is 1797 $\mathrm{mA} \mathrm{h} \mathrm{g}{ }^{-1}$, followed by a high reversible charge capacity of 1173 $\mathrm{mA} \mathrm{h} \mathrm{g}{ }^{-1}$. Thus the initial coulombic efficiency reaches $65.3 \%$ and stabilizes at $\sim 99 \%$ after $1^{\text {st }}$ cycle. As mentioned previously, the irreversible capacity loss generally results from the SEI layer and/or electrolyte decomposition. No obvious capacity decay in subsequent cycles is observed, and the cell keeps a high capacity retention of $1029 \mathrm{~mA} \mathrm{~h} \mathrm{~g}^{-1}$ after 100 cycles. The cycling performance is competitive compared to some other $\mathrm{Co}_{3} \mathrm{O}_{4}$ electrodes with complexed nanostructures or carbonaceous materials modified $\mathrm{Co}_{3} \mathrm{O}_{4}$ composites, such as carbon-doped $\mathrm{Co}_{3} \mathrm{O}_{4}$ hollow nanofibers $\left(1121 \mathrm{~mA} \mathrm{~h} \mathrm{~g}^{-1}\right.$ after 100 cycles at 200 $\left.\mathrm{mA} \mathrm{g}^{-1}\right),{ }^{[19]}$ and carbon-encapsulated $\mathrm{CO}_{3} \mathrm{O}_{4}$ nanoparticles (1413 $\mathrm{mA} \mathrm{h} \mathrm{g}{ }^{-1}$ at $100 \mathrm{~mA} \mathrm{~g}^{-1}$ after 100 cycles). ${ }^{[20]}$
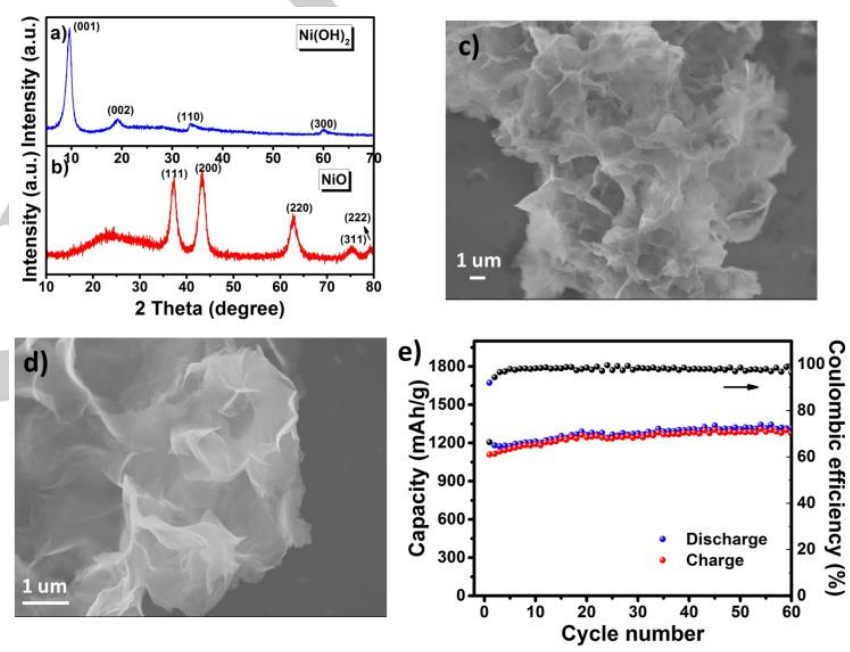

Figure 4. XRD patterns of as-prepared products: (a) $\mathrm{Ni}(\mathrm{OH})_{2}$ and (b) $\mathrm{NiO}$ SEM images of as-prepared products: (c) $\mathrm{Ni}(\mathrm{OH})_{2}$ and (d) NiO. (e) Cycling performance of $\mathrm{NiO}$ nanosheets as anode materials of LIB in the voltage window of $0.001-3.0 \mathrm{~V}\left(\mathrm{vs}\right.$. $\mathrm{Li}^{\prime} \mathrm{Li}^{+}$) at a current density of $200 \mathrm{~mA} \mathrm{~g}^{-1}$.

Based on the successful synthesis of $\mathrm{Co}(\mathrm{OH})_{2}$ and $\mathrm{Co}_{3} \mathrm{O}_{4}$ nanosheets, some other analogue nanosheets including binary and ternary transition metal oxides $\left(\mathrm{NiO}\right.$ and $\left.\mathrm{NiCO}_{2} \mathrm{O}_{4}\right)$ were also prepared by the same synthesis procedure, and their electrochemical performances as anodes for LIBs were preliminarily evaluated. As shown in Figure $4 \mathrm{a}, \alpha-\mathrm{NiOH}$ with a hexagonal layered structure (JCPDS Card No.22-0444) was acquired by the solvothermal process at $120^{\circ} \mathrm{C}$ for $4 \mathrm{~h}$. The SEM image in Figure 4c shows a 2D sheet-like structure of $\alpha$ $\mathrm{NiOH}$. The $\alpha-\mathrm{NiOH}$ nanosheets are uniform and exhibit gauzelike morphology. $\mathrm{NiO}$ nanosheets were obtained after the same heat treatment process as $\mathrm{Co}_{3} \mathrm{O}_{4}$, which can be indexed to a cubic phase structure (JCPDS Card No. 47-1409) as shown in Figure $4 \mathrm{~b}$. NiO inherits the morphology of $\alpha-\mathrm{NiOH}$ nanosheets. As a proof-of-concept application, the lithium storage performance of $\mathrm{NiO}$ nanosheets is demonstrated. The $\mathrm{NiO}$ nanosheets deliver a high charge capacity of $1109 \mathrm{~mA} \mathrm{~h} \mathrm{~g}^{-1}$ with an initial coulombic efficiency of $66.3 \%$. As presented in Figure 
$4 \mathrm{e}$, the $\mathrm{NiO}$ nanosheet electrode shows excellent cycling stability at $200 \mathrm{~mA} \mathrm{~g}^{-1}$, and a high specific capacity of $1314 \mathrm{~mA} \mathrm{~h}$ $\mathrm{g}^{-1}$ is sustained with a relatively high coulombic efficiency of $\sim 99 \%$ over 60 cycles. $\mathrm{NiCo}_{2} \mathrm{O}_{4}$ possesses a spinel structure with $\mathrm{Ni}$ occupying the octahedral sites and Co occupying both tetrahedral and octahedral sites. Given $\mathrm{Ni}$ and $\mathrm{Co}$ exhibit a mixture of oxidation states, $\mathrm{NiCO}_{2} \mathrm{O}_{4}$ possesses much higher electrical conductivity than $\mathrm{NiO}$ and $\mathrm{Co}_{3} \mathrm{O}_{4}$, and this unique property makes $\mathrm{NiCo}_{2} \mathrm{O}_{4}$ very attractive towards energy storage/conversion and catalysis applications. ${ }^{[21]} \mathrm{Ni}(\mathrm{OH})_{2^{-}}$ $\mathrm{Co}(\mathrm{OH})_{2}$ (denoted as $\mathrm{NiCO}_{2}(\mathrm{OH})_{6}$ ) solid solution was firstly prepared as precursor to synthesize $\mathrm{NiCO}_{2} \mathrm{O}_{4}$ nanosheets by the similar process. The hydroxide solid-solution keeps the hexagonal layered structure, as shown in Figure $5 \mathrm{a}$. It can be observed that the as-prepared $\mathrm{NiCO}_{2}(\mathrm{OH})_{6}$ also exhibits very flexible sheet-like 2D morphology (Figure $5 \mathrm{c}$ ). After annealing in air at $300{ }^{\circ} \mathrm{C}$ for $2 \mathrm{~h}$, cubic $\mathrm{NiCO}_{2} \mathrm{O}_{4}$ is obtained as shown in Figure 5b (JCPDF Card No. 20-0781). The $\mathrm{NiCO}_{2} \mathrm{O}_{4}$ maintains the ultrathin $2 \mathrm{D}$ nanosheet structure as well as large in-plane area of up to several microns. As shown in Figure $5 \mathrm{~d}, \mathrm{NiCo}_{2} \mathrm{O}_{4}$ nanosheet electrode shows considerably stable cycling performance for lithium storage, delivering $1346 \mathrm{mAh} \mathrm{g}^{-1}$ during the $60^{\text {th }}$ cycle at $200 \mathrm{~mA} \mathrm{~g}^{-1}$. The encouraging lithium storage performances of $\mathrm{NiO}$ and $\mathrm{NiCO}_{2} \mathrm{O}_{4}$ nanosheets further confirms the unique superiority of $2 \mathrm{D}$ nanomaterials for energy storage applications.
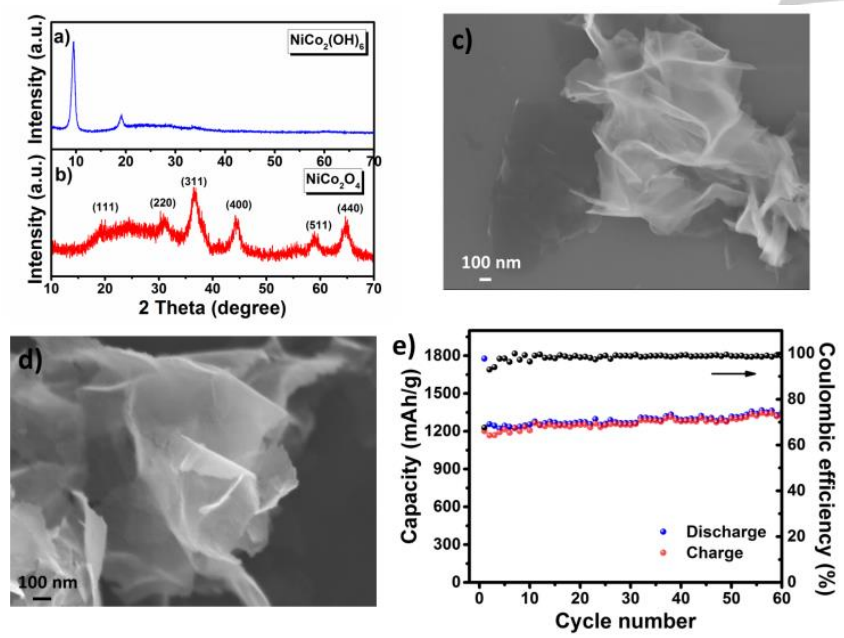

Figure 5. XRD patterns of as-prepared products: (a) $\mathrm{NiCO}_{2}(\mathrm{OH})_{6}$ and (b) $\mathrm{NiCO}_{2} \mathrm{O}_{4}$. SEM images of as-prepared products: (c) $\mathrm{NiCO}_{2}(\mathrm{OH})_{6}$ and (d) $\mathrm{NiCO}_{2} \mathrm{O}_{4}$. (e) Cycling performance of $\mathrm{NiCo}_{2} \mathrm{O}_{4}$ nanosheets as anode materials of LIB in the voltage window of $0.001-3.0 \mathrm{~V}$ (vs. $\mathrm{Li}^{\prime} \mathrm{Li}^{+}$) at a current density of $200 \mathrm{~mA} \mathrm{~g}^{-1}$.

\section{Conclusions}

In summary, a universal and scalable process was developed to prepare $\mathrm{Ni} / \mathrm{Co}$-based hydroxide and oxide nanosheets. The performances of the oxide nanosheets as anodes for rechargeable batteries were investigated. Benefiting from the unique properties of the $2 \mathrm{D}$ morphology, the $\mathrm{Co}_{3} \mathrm{O}_{4}$ nanosheets exhibit very impressive sodium (150 $\mathrm{mA} \mathrm{h} \mathrm{g}^{-1}$ at $10.0 \mathrm{~A} \mathrm{~g}^{-1}$, and $404 \mathrm{~mA} \mathrm{~h} \mathrm{~g}^{-1}$ after 100 cycles at $0.1 \mathrm{~A} \mathrm{~g}^{-1}$ ) and lithium (1029 mA $\mathrm{h} \mathrm{g}^{-1}$ after 100 cycles at $0.2 \mathrm{~A} \mathrm{~g}^{-1}$ ) storage capabilities with high specific capacity, good rate capability and cycling life. As a proof-of-concept, the performances of $\mathrm{NiO}$ and $\mathrm{NiCo}_{2} \mathrm{O}_{4}$ nanosheets were also evaluated as anodes for LIBs, and both materials delivered high-capacity and durable lithium storage performances (1314 and $1346 \mathrm{mAh} \mathrm{g}^{-1}$ for $\mathrm{NiO}$ and $\mathrm{NiCo}_{2} \mathrm{O}_{4}$, respectively, after 60 cycles at $0.2 \mathrm{~A} \mathrm{~g}^{-1}$ ). The present results demonstrate the great potential of $2 \mathrm{D}$ metal oxide nanomaterials for energy storage/conversion-related applications.

\section{Experimental Section}

\section{Synthesis of Ni/Co-based hydroxides and oxides nanosheets}

In a typical synthesis of cobalt hydroxide and $\mathrm{Co}_{3} \mathrm{O}_{4}$ nanosheets, $1.8 \mathrm{mmol} \mathrm{Co}\left(\mathrm{NO}_{3}\right)_{2} \cdot 6 \mathrm{H}_{2} \mathrm{O}$ and $3.6 \mathrm{mmol}$ hexamethylene tetramine (HMT) were firstly dissolved in a mixed solvent containing $16 \mathrm{~mL}$ deionized water and $24 \mathrm{~mL}$ ethylene glycol (EG) under vigorous stirring. Consequently, the pink solution was transferred to a Teflon lined stainless-steel autoclave with a capacity of $50 \mathrm{~mL}$. The autoclave was sealed and maintained at $120{ }^{\circ} \mathrm{C}$ for $4 \mathrm{~h}$ in an electric oven. The autoclave cooled down naturally after reaction, and light green products were collected by centrifugation followed by repeated washing with deionized water. Finally, the products were freeze-dried for two days, obtaining cobalt hydroxide nanosheets. $\mathrm{Co}_{3} \mathrm{O}_{4}$ nanosheets were obtained by annealing the cobalt hydroxide nanosheets in air at $300{ }^{\circ} \mathrm{C}$ for $2 \mathrm{~h}$ with a heating rate of $5{ }^{\circ} \mathrm{C} \mathrm{min}{ }^{-1}$. For the synthesis of nickel hydroxide and $\mathrm{NiO}$ nanosheets, the experimental procedure was the same as the aforementioned steps except that the metal ion precursor was $1.8 \mathrm{mmol} \mathrm{Ni}\left(\mathrm{NO}_{3}\right)_{2} \cdot 6 \mathrm{H}_{2} \mathrm{O}$. For the synthesis of nickel/cobalt hydroxide and $\mathrm{NiCO}_{2} \mathrm{O}_{4}$ nanosheets, $0.6 \mathrm{mmol} \quad \mathrm{Ni}\left(\mathrm{NO}_{3}\right)_{2} \cdot 6 \mathrm{H}_{2} \mathrm{O}$ and $1.2 \mathrm{mmol}$ $\mathrm{Co}\left(\mathrm{NO}_{3}\right)_{2} \cdot 6 \mathrm{H}_{2} \mathrm{O}$ were used as the metal ion precursors. The hydroxide precursors were annealed in air at $300{ }^{\circ} \mathrm{C}$ for $2 \mathrm{~h}$ to obtain the oxide counterparts.

\section{Materials characterization}

The phase and surface chemical state were determined by X-ray diffraction (XRD, MMA GBC, Australia). The morphology of the as-prepared products was observed by a JEOL JSM-7500FA field-emission scanning electron microscope (FESEM) and a JEOL 2010 transmission electron microscope (TEM). Hermogravimetric analysis (TGA, Q500) was carried out from room temperature to $450{ }^{\circ} \mathrm{C}$ at a heating rate of $10 \mathrm{~K} \mathrm{~min}^{-1}$ in air.

\section{Electrochemical measurements}

The active material $\left(\mathrm{Co}_{3} \mathrm{O}_{4}, \mathrm{NiO}\right.$, or $\mathrm{NiCO}_{2} \mathrm{O}_{4}$ nanosheets) was thoroughly mixed with carbon nanotubes (CNTs) and poly(vinyl difluoride) (PVDF) at a weight ratio of $7: 2: 1$ in $\mathrm{N}$ methylpyrrolidone solvent to form a homogeneous slurry. The cell working electrodes were prepared by painting the slurry on copper foil, followed by vacuum drying at $80{ }^{\circ} \mathrm{C}$ overnight. The coin-type half-cells were assembled in an Ar-filled glove box with both $\mathrm{H}_{2} \mathrm{O}$ and $\mathrm{O}_{2}$ levels less than $1 \mathrm{ppm}$. For SIBs, metallic $\mathrm{Na}$ foil was employed as the counter/reference electrode, and Whatman GF/D microfiber filter paper was used as the separator. 
$1 \mathrm{M} \mathrm{NaClO}_{4}$ dissolved in propylene carbonate (PC) with $5 \%$ fluoroethylene carbonate (FEC) additive was chosen as the electrolyte. For LIBs, lithium foils were used as counter/reference electrodes. Celgard 2400 membrane was used as separator, and $1 \mathrm{M} \mathrm{LiPF}_{6}$ dissolved in ethylene carbonate (EC)/dimethyl carbonate (DMC) $(1 / 1, w / w)$ was used as electrolyte. Galvanostatic charge/discharge testing was conducted in the voltage range of 0.01-3.0 V using a NEWARE multichannel battery test system.

\section{Acknowledgements}

This work was financially supported by Australian Research Council (ARC) DECRA Grant (DE160100596) and ARC Discovery Project (DP160102627). Y.Z. Jiang acknowledges support from the National Natural Science Foundation of China (Grant No. 21373184) and the Public Projects of Zhejiang Province (2015C31039).

Keywords: Nanosheets - Transition metal oxide . Anode $\cdot$ Sodium ion batteries $\cdot$ Lithium ion batteries

11] a) D. C Tsui, T Englert A Y Cho and A C Gossard, Phy Rev. Lett. 1980, 44, 341-344; b) P. K. Kannan, D. J. Late, H. Morgan and C. S. Rout, Nanoscale 2015, 7, 13293-13312; c) Y. H. Hu, H. Wang and B. Hu, Chemsuschem 2010, 3, 782-796; d) J. H. Liu and X. W. Liu, Adv. Mater. 2012 24, 4097-4111.

[2] a) W.-B. Luo, S.-L. Chou, J.-Z. Wang, Y.-M. Kang, Y.-C. Zhai and H.-K. Liu, Chemical Communications 2015, 51, 8269-8272; b) X. Huang, Z. Y. Yin, S. X. Wu, X. Y. Qi, Q. Y. He, Q. C. Zhang, Q. Y. Yan, F. Boey and H. Zhang, Small 2011, 7, 1876-1902; c) Y. Q. Sun, Q. O. Wu and G. Q. Shi, Energy Environ. Sci. 2011, 4, 1113-1132.

[3] a) H. T. Tan, W. Sun, L. Wang and Q. Yan, ChemNanoMat 2016, 2, 562 577; b) G. Zhang, H. J. Liu, J. H. Qu and J. H. Li, Energy Environ. Sci. 2016, 9 1190-1209; c) C. L. Tan and H. Zhang, Nat. Commun. 2015, 6, 1-13; d) M. R. Kaiser, X. Liang, K. Konstantinov, H.-K. Liu, S.-X. Dou and J.-Z. Wang, Chemistry-a European Journal 2015, 21, 10061-10069; e) Z. Sun, T. Liao, Y Dou, S. M. Hwang, M. S. Park, L. Jiang, J. H. Kim and S. X. Dou, Nat. Commun. 2014, 5, 1-9.

4] a) M. D. Slater, D. Kim, E. Lee and C. S. Johnson, Adv. Funct. Mater. 2013 23, 947-958; b) N. Yabuuchi, K. Kubota, M. Dahbi and S. Komaba, Chem. Rev. 2014, 114, 11636-11682; c) Z. G. Yang, J. L. Zhang, M. C. W. Kintner-Meyer, X. C. Lu, D. W. Choi, J. P. Lemmon and J. Liu, Chem. Revi. 2011, 111, 3577 3613; d) B. Dunn, H. Kamath and J. M. Tarascon, Science 2011, 334, 928 935; e) S. Yuan, S. Wang, L. Li, Y. H. Zhu, X. B. Zhang and J. M. Yan, ACS Appl Mater Interfaces 2016, 8, 9178-9184; f) S. Wang, S. Yuan, Y.-B. Yin, Y. H. Zhu, X.-B. Zhang and J.-M. Yan, Part. Part. Syst. Charact. 2016, 33, 493 499; g) X. Wang, Y. Chen, O. G. Schmidt and C. Yan, Chem. Soc. Rev. 2016 $45,1308-1330$

[5] a) J. Jiang, Y Y Li, J. P. Liu, X. T. Huang, C. Z Yuan and X. W. Lou, Adv. Mater. 2012, 24, 5166-5180; b) M. V. Reddy, G. V. S. Rao and B. V. R Chowdari, Chem. Rev. 2013, 113, 5364-5457; c) C. B. Zhu, X. K. Mu, P. A. van Aken, Y. Yu and J. Maier, Angew. Chem. Int. Ed. 2014, 53, 2152-2156; d) R. Alcantara, M Jaraba, P Lavela and J. L. Tirado, Chem Mater 2002, 14, 2847-2848; e) L. David, R. Bhandavat and G. Singh, ACS Nano 2014, 8 1759-1770.

[6] a) W. Sun, X. Rui, D. Yang, Z. Sun, B. Li, W. Zhang, Y. Zong, S. Madhavi, S. Dou and Q. Yan, Acs Nano 2015, 9, 11371-11381; b) Y. Jiang, D. Zhang, Y. Li, T. Yuan, N. Bahlawane, C. Liang, W. Sun, Y. Lu and M. Yan, Nano Energy $2014,4,23-30$

[7] a) W. Sun, X. Rui, J. Zhu, L. Yu, Y. Zhang, Z. Xu, S. Madhavi and Q. Yan J. Power Sources 2015, 274, 755-761; b) J. Wang, J. Liu, H. Yang, D. Chao, J. Yan, S. V. Savilov, J. Lin and Z. X. Shen, Nano Energy 2016, 20, 1-10; c) J. S. Cho, J. K. Lee and Y. C. Kang, Sci. Rep. 2016, 6, 23699-23711; d) Y. J. Zhai, H. Z. Mao, P. Liu, X. C. Ren, L. Q. Xu and Y. T. Qian, J. Mater. Chem. A 2015, 3, 16142-16149.

[8] a) X.-I. Huang, R.-z. Wang, D. Xu, Z.-I. Wang, H.-g. Wang, J.-j. Xu, Z. Wu, Q.-c. Liu, Y. Zhang and X.-b. Zhang, Adv. Funct. Mater. 2013, 23, 4345-4353 b) X.-I. Huang, J. Chai, T. Jiang, Y.-J. Wei, G. Chen, W.-q. Liu, D. Han, L. Niu L. Wang and X.-b. Zhang, J. Mater. Chem. 2012, 22, 3404; c) X.-I. Huang, X Zhao, Z.-I. Wang, L.-m. Wang and X.-b. Zhang, J. Mater. Chem. 2012, 22, 3764; d) T. Yang, T. Qian, M. Wang, X. Shen, N. Xu, Z. Sun and C. Yan, Adv. Mater. 2016, 28, 539-545.

[9] a) S. Das, M. Kim, J.-w. Lee and W. Choi, Criti. Rev. Solid State 2014, 39 231-252; b) C. L. Tan and H. Zhang, Chem. Soc. Rev. 2015, 44, 2713-2731.

[10] a) K. Varoon, X. Zhang, B. Elyassi, D. D. Brewer, M. Gettel, S. Kumar, J. A. Lee S. Maheshwari, A Mittal, C. Y Sung, M. Cococcioni, L. F Francis, A. V. McCormick, K. A. Mkhoyan and M. Tsapatsis, Science 2011, 334, 72-75; b) V. Nicolosi, M. Chhowalla, M. G. Kanatzidis, M. S. Strano and J. N. Coleman, Science 2013, 340, 1420-1437; c) J. N. Coleman, M. Lotya, A. O'Neill, S. D. Bergin, P. J. King, U. Khan, K Young, A Gaucher, S. De, R. J. Smith, I. V. Shvets, S. K. Arora, G. Stanton, H. Y. Kim, K. Lee, G. T. Kim, G. S. Duesberg T. Hallam, J. J. Boland, J. J. Wang, J. F. Donegan, J. C. Grunlan, G. Moriarty, A. Shmeliov, R. J. Nicholls, J. M. Perkins, E. M. Grieveson, K. Theuwissen, D. W. McComb, P. D. Nellist and V. Nicolosi, Science 2011, 331, 568-571.

[11] a) W.-J. Li, S.-L. Chou, J.-Z. Wang, Y.-M. Kang, J.-L. Wang, Y. Liu, Q.-F Gu, H.-K. Liu and S.-X. Dou, Chem. Mater. 2015, 27, 1997-2003; b) A. Reina X. T. Jia, J. Ho, D. Nezich, H. B. Son, V. Bulovic, M. S. Dresselhaus and J. Kong, Nano Lett. 2009, 9, 30-35; c) Y. H. Lee, X. Q. Zhang, W. J. Zhang, M. T.

Chang, C. T. Lin, K. D. Chang, Y. C. Yu, J. T. W. Wang, C. S. Chang, L. J. Li and T. W. Lin, Adv. Mater. 2012, 24, 2320-2325

[12] S. Jeong, D. Yoo, J.-t. Jang, M. Kim and J. Cheon, J. Am. Chem. Soc 2012, 134, 18233-18236.

[13] M. M. Rahman, A. M. Glushenkov, T. Ramireddy and Y. Chen, Chemi. Commun. 2014, 50, 5057-5060.

[14] J. Vetter, P. Novák, M. R. Wagner, C. Veit, K. C. Möller, J. O. Besenhard M. Winter, M. Wohlfahrt-Mehrens, C. Vogler and A. Hammouche, J. Powe Sources 2005, 147, 269-281.

[15] Z. Jian, P. Liu, F. Li, M. Chen and H. Zhou, J. Mater. Chem. A 2014, 2, 13805-13809.

[16] W. K. Pang, S. Kalluri, V. K. Peterson, N. Sharma, J. Kimpton, B. Johannessen, H. K. Liu, S. X. Dou and Z. Guo, Chemistry of Materials 2015 27, 3150-3158.

[17] Y. Wang, C. Wang, Y. Wang, H. Liu and Z. Huang, J. Mater. Chem. A 2016, 4, 5428-5435.

[18] K. He, F. Lin, Y. Zhu, X. Yu, J. Li, R. Lin, D. Nordlund, T. C. Weng, R. M. Richards, X. Q. Yang, M. M. Doeff, E. A. Stach, Y. Mo, H. L. Xin and D. Su, Nano Lett 2015, 15, 5755-5763.

[19] C. Yan, G. Chen, X. Zhou, J. Sun and C. Lv, Adv. Funct. Mater. 2016, 26, 1428-1436.

[20] X. Leng, S. Wei, Z. Jiang, J. Lian, G. Wang and Q. Jiang, Sci. Rep. 2015 , 5, 16629-16639.

[21] a) G. Q. Zhang, H. B. Wu, H. E. Hoster, M. B. Chan-Park and X. W. Lou, Energy Environ. Sci. 2012, 5, 9453; b) S. Abouali, M. A. Garakani, Z. L. Xu and J. K. Kim, Carbon 2016, 102, 262-272; c) L. L. Liu, J. Wang, Y. Y. Hou, J. Chen, H. K. Liu, J. Z. Wang and Y. P. Wu, Small 2016, 12, 602-611. 


\section{Entry for the Table of Contents}

Layout 1:

\section{FULL PAPER}

A universal process that can be extended to scale-up is developed for synthesizing ultrathin Co/Ni-based hydroxides and oxides. For sodium storage, the $\mathrm{Co}_{3} \mathrm{O}_{4}$ nanosheets exhibit excellent rate capability (e.g. $179 \mathrm{~mA}$ $\mathrm{h} \mathrm{g}^{-1}$ at $7.0 \mathrm{~A} \mathrm{~g}^{-1}$ and $150 \mathrm{~mA} \mathrm{~h} \mathrm{~g}^{-1}$ at 10.0 $\mathrm{A} \mathrm{g} \mathrm{g}^{-1}$ ) and promising cycling performance (404 $\mathrm{mA} \mathrm{h} \mathrm{g}^{-1}$ after 100 cycles at $\left.0.1 \mathrm{~A} \mathrm{~g} \mathrm{~g}^{-1}\right)$.

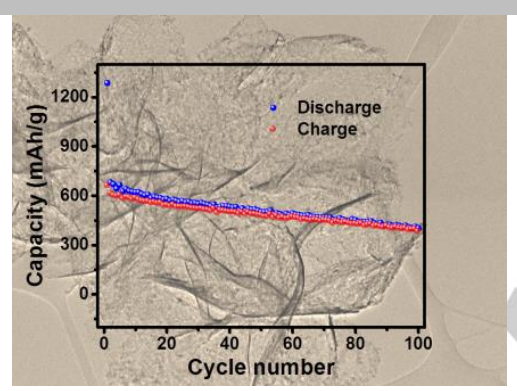

Dan Zhang, ${ }^{[a, b]}$ Wenping Sun, ${ }^{* a]} Y u$ Zhang, ${ }^{[a]}$ Wenbin Luo, ${ }^{[a]}$ Yinzhu Jiang, ${ }^{*}{ }^{[b]}$ Shi Xue Dou ${ }^{[a]}$

Page No. - Page No.

Two-dimensional Cobalt/NickelBased Oxide Nanosheets for HighPerformance Sodium and Lithium Storage 